\title{
Statistical modelling: the old standardisation problem in disguise?
}

\author{
J P VANDENBROUCKE \\ From Leiden University Hospital, Leiden, The Netherlands
}

The debate about the relative merits of direct and indirect standardisation was started by Yule in $1934 ;^{1}$ it was mentioned in passing by a few others ${ }^{2}$ and recently revitalised by Miettinen. ${ }^{4}$ It is now firmly settled in prominent textbooks on epidemiology..$^{5-7}$ The debate has resulted in the prevailing paradigm that a standardisation procedure is an adjustment by weighting, which produces an artificial pooled value across strata. We need this artifact to make comparisons, eg to calculate an unconfounded relative risk. Certainly, the crude comparison, the unadjusted one, is wrong. The adjusted comparison is valid, yet the size of the difference in risk between two groups can be very subtly influenced by the choice of the standard.

In consequence, prudent editors of the better journals do not accept overall standardised figures at face value. They want at least one table with detailed stratum specific information, to assure themselves that the inference by the standardisation procedure is right. At a minimum, they want to ascertain that one group has indeed a higher risk than the other in most of the strata. An alternative is a test for homogeneity of the relative risk or the risk difference over the strata. This is a test for interaction, which is known to be rather insensitive since it lacks statistical power, except if an interaction is extreme - and even then, the direction of the interaction (positive or negative) is the only really reliable information from the data. ${ }^{89}$

This wariness about the standardisation procedure contrasts with the great enthusiasm of epidemiologists in accepting statistical models. Now, what else is a model, except for another adjustment procedure? Usually, the epidemiologist has recourse to the statistical model when cross classification becomes too detailed and tabular methods break down. ${ }^{10}$ Anyone who has ever performed the healthy exercise, however, of calculating with the same data set a directly standardised relative risk (preferably with different standards), a standardised mortality ratio, a MantelHaenszel relative risk, a relative risk by Poisson modelling, and one by a logistic or Cox regression, will have observed that each time one obtains a different answer. Sometimes the answers are grossly different; most of the time only slightly so. A nice artificial example that can be used for a start is found in a recent textbook on cohort analysis. ${ }^{7}$

From these observations it follows that it is necessary to accept that the relative risk or risk difference, or any other coefficient as calculated in a statistical model is another artificial number. Not only is the weighing procedure invisible-it happens inside the computer and cannot be checked by hand except if very gross strata are used-but it also involves extra assumptions about the shape of the relation between exposure and disease and about the mutual dependency of several risk factors. ${ }^{11} 12$ Beside these older sores, the new modelling approach is beset by a new problem, however. There is an extra arbitrariness which is aggravated by the advent of the modern high speed desk computer. Given a few hundred cases and a dozen variables, some millions of statistical models can be specified: all possible combinations of any number of explanatory variables, combined with all types of variable transformations, in turn to be combined with all possible combinations of lower and higher order interaction terms. We pass over the choice of the model, relative risk or risk difference, for which an infinite variety, covering all intermediate possibilities was recently proposed. ${ }^{13}$ Given this situation, it is a certainty that dozens of wildly different models, subject to very different interpretations, will fit the data equally well. This bewildering array of possibilities calls for restriction and simplicity, maybe for the use of Occam's razor. Model building should remain simple and have a strong a priori footing, which will guide our a posteriori interpretation of the coefficients. 
Otherwise, the arbitrariness could become a liability to epidemiology as it removes the interpretation of our data even further from biological reality. ${ }^{14}$ The relative performance of these different models can indeed no longer be checked by visual methods, since such models allow all kinds of straight and curved lines to be drawn through almost empty data cells. A safe strategy might be to perform stratified analysis and analysis by statistical modelling on a hand in hand basis. ${ }^{12}$

The conclusion is inescapable that a model is only another way of summarising data. A regression coefficient, even its antilogarithm which denotes a relative risk in some of the sophisticated models, has no absolute meaning; it pertains only to the data, the specific model and the model assumptions at hand. ${ }^{15}$ In theory, discovering "Laws of Nature" linking exposure and disease is the aim of our trade. Relative risks or risk differences would be the "Natural constants" for such "Laws of Nature". Our present application of statistical models is such a far cry from this ideal, however, that to our dismay modern computerised data analysis by statistical models plunges us into an abyss of total subjectivity. Indeed, the strongest guide to data analysis will have to become the scientist's opinion, which is usually firmly set. In contrast, data driven analysis will become more and more anachronistic as computer and model power increase: just too many different models can be churned out of the machine. In the end, we might advise our junior collaborators to plan their data analysis very carefully and rigorously beforehand, just as in the old days, when a "computer" was still a human doing calculations very slowly and tediously, returning output of complex matrix inversions only after days or weeks.

Address for correspondence and reprints: Professor J P Vandenbroucke, MD, PhD, Department of Clinical Epidemiology, Leiden University Hospital, Building 1
CO-P, PO Box 9600, 2300 RC Leiden, The Netherlands.

\section{References}

${ }^{1}$ Yule V. On some points relating to vital statistics, more especially statistics of occupational mortality. $J R$ Stat Soc 1934; 97: 1-84.

${ }^{2}$ Kahn HA. The Dorn study of smoking and mortality among U.S. Veterans. In: Haenszel W, ed. Epidemiological approaches to the study of cancer and other chronic diseases. Natl Cancer Inst Monograph 1966; 19: $1-125$.

${ }^{3}$ Haenszel W, Kurihara M. Studies of Japanese migrants. I. J Natl Cancer Inst 1968; 40: 43-68.

${ }^{4}$ Miettinen OS. Standardization of risk ratios. Am J Epidemiol 1972; 96: 383-8.

${ }^{5}$ Monson RR. Occupational epidemiology. Boca Raton: CRC Press, 1980.

${ }^{6}$ Rothman KJ. Modern epidemiology. Boston: Little, Brown, 1986.

${ }^{7}$ Breslow N, Day N. Statistical methods in cancer research. The design and analysis of cohort studies. New York: Oxford University Press, 1987:92.

${ }^{8}$ Smith PG. Issues in the design of case-control studies: matching and interaction effects. (Presented at the 8th meeting of the Netherlands Epidemiological Society) Tijdschrift Sociale Gezandheidszorg 1983; 61: 755-60.

${ }^{9}$ Miettinen OS. Theoretical epidemiology. Principles of occurrence research in medicine. New York: Wiley, 1985.

10 Truett J, Cornfield J, Kannel W. A multivariate analysis of the risk of coronary heart disease in Framingham. $J$ Chron Dis 1967; 20: 511-24.

11 Robins JM, Greenland S. The role of model selection in causal inference from non-experimental data. Am J Epidemiol 1986; 123: 392-402.

12 Vandenbroucke JP. Should we abandon statistical modelling altogether? Am J Epidemiol 1987; 126: 10-3.

13 Breslow NE. Storer BE. General relative risk function for? case-control studies. Am J Epidemiol 1985; 122: 149-62.

14 Gordis L. Challenges to epidemiology in the next decade. Am J Epidemiol 1988; 128: 1-9.

${ }^{15}$ Achen $\mathrm{CH}$. Interpreting and using regression (Sage University paper series on Quantitative Applications in the Social Sciences, No 7-29). Beverly Hills and London: Sage Publications, 1982.

Accepted for publication February 1989 